\title{
Sedentarisation of Tibetan nomads in China: Implementation of the Nomadic settlement project in the Tibetan Amdo area; Qinghai and Sichuan Provinces
}

Jarmila Ptackova

Correspondence: jptackova@gmail. com

Humboldt University, Department of Central Asia, Institute for Asian and African Studies, Invalidenstrasse 118, 10115 Berlin, Germany

\begin{abstract}
Sedentarisation efforts have been part of the Chinese policy on the Tibetan grassland since the 1960s. These efforts increased significantly after the introduction of the Opening of the west (Chin: 西部大开发 xibu da kaifa) development strategy. The aim of the sedentarisation programs is mainly to improve the grassland ecosystem and also the socio-economic situation of nomadic households. Nevertheless the program aims do not concentrate primarily on the nomads and how they cope with the situation and new lifestyle in the urban settlements. Are the settlement measures going to solve the situation on the grassland in the west of China, or is the hasty implementation going to bring further social problems for Tibetan nomads, that the Central Government will have to solve? This article will not be able to answer all these important questions as the resettlement process has not been completely accomplished yet. The article focuses on recently implemented projects in the sequence of sedentarisation programs, the so-called Nomadic settlement (Chin: 游牧 民定居 you mumin dingju) and describes the main elements of this project according to governmental documents, interviews with responsible persons and its implementation in areas of Maqin and Zeku Counties in Qinghai Province and Hongyuan County in Sichuan Province. The article provides information on the outcome of the project, the recent situation and offers a basis for further research.

Keywords: Tibetan pastoralist, China, settlement policy, sedentarisation
\end{abstract}

\section{Background}

Since 2009 the sedentarisation efforts of the Chinese government have become highly visible on the grassland area of Amdo, a Tibetan region in western China. However, the settling process is not an innovation, since it was started some decades ago, with the central Government interfering in the traditional way of nomadic life, trying to reeducate the nomads (Gruschke 2006,). After the collapse of the communes in 1981, new measures were taken to facilitate the sedentarisation of Tibetan nomads. An important step was the land distribution to single households within the Household Responsibility System during the decollectivisation period of the 1980s. With each household gaining use rights for its part of pastureland, fences had to be introduced to reduce quarrels concerning property matters (Yeh 2003). Additionally, the fences

(C) 2011 Ptackova; licensee Springer. This is an Open Access article distributed under the terms of the Creative Commons Attribution License (http://creativecommons.org/licenses/by/2.0) , which permits unrestricted use, distribution, and reproduction in any medium, provided the original work is properly cited. 
demarcated the division of the grassland. With defined winter grassland property it was easier for the nomads to raise permanent houses. This was strongly supported by the government through the Project to increase living comfort (Chin: 温饱工程 wenbao gongcheng) introduced in 1978 and the Four completions project (Chin: 四配套 sipeitao) of the 1990s (ADGM II 1994). The regulations of these projects were similar to the recent Nomadic settlement project and already included governmental support to erect fences, plant grass, and construct permanent houses and animal sheds at the winter pasture of each household (ADGM III 2003).

The sedentarisation process has intensified significantly after the implementation of the Opening of the west development strategy (Du2006). So far, construction of settlements is part of various programs administered by different governmental institutions. The major resettlement goals stated are environmental protection of degraded grassland, on one hand, and improvement of the socio-economical situation of Tibetan pastoralist households on the other hand. Furthermore, the relocation of nomads into urban settlements aids in the political control of the Tibetan plateau ${ }^{\mathrm{a}}$. The worsening of the grassland and at least on a statistical basis, the low income of the nomads are facts and at least in theory some of the governmental programs seem to be beneficial in solving these issues. Nevertheless, the implementation of these programs often does not pay enough attention to the subjects who are affected by the changes, namely to the Tibetan nomads themselves. The hasty implementation makes the people change their lifestyle from one day to another, without having enough time to adapt to the new situation naturally. The lack of the nomads' experience with urban life might bring serious problems for the settlement communities and for the Central Government in the future.

The most recently implemented program by the time of this study in 2007-2009 that includes settlement constructions, is the so-called Nomadic settlement project, in Tibetan areas. At least in the Tibetan areas of Qinghai Province, this program might accomplish all previous settlement efforts as it concerns all remaining Tibetan nomadic households without a permanent house or with an unsteady house in danger of collapse (Chin: 无房户和危房户 wu fang hu he weifang hu). This project is based on the experiences gained during the implementation of earlier programs such as Turning pastureland into grassland (Chin: 退牧还草 tui mu huan cao) or Ecological resettlement (Chin: 生态移民 shengtai yimin) and is aimed to complete these programs.

\section{Methods and study areas}

Based upon qualitative interviews with both local officials and Tibetan nomads in the Amdo region involved in the implementation of settlement programs between 2007 and 2009, and scrutiny of available government documents describing the settlement issue, this article will analyse the development and main purposes of sedentarisation efforts, focusing on the Nomadic settlement project. Three case study areas are described as examples of implementation. Zeku County, which is one of the poorest counties of Qinghai Province (ADGM I 2009, and ADGM VI 2007), Maqin County, which is counted among the richest nomadic counties of Qinghai Province, and for comparison the neighbouring grassland area of Hongyuan County in Sichuan Province. The grassland conditions in Sichuan Province, represented by Hongyuan County are 
much better than in Qinghai Province. Nevertheless, large scale sedentarisation is being implemented also here.

In the three selected areas we find three different types of implementation of the Nomadic settlement project, described below. The sedentarisation process of Tibetan nomads in China has only recently reached its peak and is still proceeding. Some households have moved to settle just a few years ago and other households, especially those involved in the Nomadic settlement project, are about to start their life in a settlement now. Therefore it is not possible yet to make a general summary about the final impact of this policy on the life of Tibetan nomads. This article serves as a starting point for further research concerning the development and change of lifestyle for the nomads after their relocation into urban settlements.

\section{The Nomadic settlement project}

In contrast to settlement programs implemented previously, such as the Turning pastureland into grassland and Ecological resettlement, the Nomadic settlement project does not shift households' every day life away from their original place and their focus on animal husbandry, or at least this shift has not yet occurred.

The Turning pastureland into grassland program, implemented since 2003 and managed by the provincial Agricultural and Animal Husbandry office concentrates on the restoration of degraded parts of the grassland. In areas with high degradation, the pastureland is completely exclosed (fenced off) and a grazing ban is set down. The grazing ban prohibits $r$ grazing for the entire year and shall be applied over a period of 10 years. Affected households are resettled and the number of their livestock significantly reduced. During the grazing ban period, the nomad households receive fodder and grain subsidies from the government (ADGM IV2008)

The Ecological resettlement, implemented within the area of the Three River Sources national nature reserve (Sanjiangyuan) since 2004 (ADGM VI 2007) and managed by the Sanjianyuan office belonging to the Development and Reform Committee of the Qinghai Province, focuses on poverty alleviation and improvement of the socio-economic situation of nomadic households. In order to help nomadic households from regions with severe grassland degradation and to let the grassland ecosystem restore itself, this program resettles households from affected regions into newly constructed settlements, which might be in the same county but are sometimes located even in a different province. Governmental subsidies help these households to temporarily cover their daily expenses. However such subsidies are not high and can hardly cover the costs of basic needs, which rose enormously after the nomads gave up their livestock. For the nomads involved, there also remains the possibility of a return back to their grassland, but only after a certain period of time defined in the resettlement contract and only after additional governmental approval, which depends on sufficient recovery of local grassland.

The Nomadic settlement project (which seems to be parallel to the Comfortable Housing project in Tibet Autonomous Region (Goldstein 2010), was implemented in Qinghai Province in 2009, and is also managed by the provincial Agricultural and Animal Husbandry office. In Qinghai Province, the project concerns 31 counties of six prefectures, Haibei, Hainan, Huangnan, Yushu, Guoluo and Haixi. All the places affected are Tibetan ethnic areas. In 2009 Qinghai Province scheduled construction of 25.710 houses with a total investment of 1.225.872.000 RMB. The money provided for 
this program comes from different administrative levels. The costs are shared by central Government, province, prefectures and counties and the nomads themselves. In the plan of 2009, the nomads were to provide $13.8 \%$ of the total costs (ADGM V 2009). The nomads' share of the settlement construction costs is a statistical statement. In reality, the local governmental institution in charge decides the method of implementation in the area under its jurisdiction, according to the financial resources supplied by the government and number of households designated to participate in the Nomadic settlement project on-site. Depending on the implementation method, the nomads have to pay a fixed share for the governmental construction or they obtain a fixed money grant from the government and are responsible for the house construction themselves.

Not all targeted nomadic households can be involved in the program at the same time. The Nomadic settlement project is scheduled to continue over the next years until the settlement constructions are completed. The number of houses built in one year depends in the first place on the annual investment of the central Government which supplies over 50\% of all expenses. The Zeku County government of Huangnan Prefecture for example hopes to accomplish this project and supply houses for all nomadic households within three years.

The Nomadic settlement project shall involve all Tibetan nomadic households without a permanent house or with an unsteady house in danger of collapse. In the project plan description this is defined as a house made of earth and wood that has not been repaired for a long time. Additional participation rules preclude previous involvement into other kinds of resettlement or settlement programs implemented within the Turning pastureland into grassland or Ecological resettlement policy. One household must have at least two family members and it must be at least two years since these family members split from another household unit (ADGM V 2009). At least during the implementation of the Ecological resettlement, household splitting was a popular solution among the nomads, enabling them to get a new house without relinquishing their pastureland and livestock. The grandparents were claimed by the nomads to be a separate household and sent to inhabit the new house in the settlement. In this way, a single household was able to keep their pastoralist base on the grassland and also obtain additionally a house situated near transport networks, from where the children had better access to school.

According to a governmental investigation, in Qinghai Province there are 134.300 households that fit the eligibility of the Nomadic settlement project (ADGM VII; 2009).

The Nomadic settlement project was designed to complete the efforts of balancing the ecology and animal husbandry started by the Turning pastureland into grassland and Ecological resettlement policies. In addition to house building, the Nomadic settlement project shall help to complete the construction works by building animal sheds, erecting grassland fencing, planting grass, establishing water pipe systems for livestock and people, building roads and constructing solar and methane gas energy facilities. In a way, the projectseems to be also a continuation of the Four completions policy implemented earlier. Modern materials such as bricks, concrete, metal and wood for pillars shall be used for the construction of new dwelling houses. To meet all the needs of a single household (no matter how many family members it has), the size of a house must be at least 60 square meters (ADGM V 2009). 


\section{Nomadic settlement project implementation}

In reality the implementation of the Nomadic settlement project varies from place to place. In Guoluo Prefecture, Qinghai Province, in 2009 the government scheduled construction of 5.128 new houses in the nomadic area. According to a Prefecture Government announcement these houses were to be built by the nomads themselves. The construction should include a house of at least 60 square meters, a toilet, an animal shed and an animal yard. To build each house unit there were $48.500 \mathrm{RMB}^{\mathrm{c}}$. According to our field research, in Maqin County, Guoluo Prefecture any nomadic household could apply to participate on this program. Even households who already possessed a stable concrete housing started to build a new house. Most households build their house by themselves. It is possible to hire labourers for the construction, but that would mean additional costs for the nomads. The new houses could be constructed optionally either at the winter grassland or in a new village settlement next to the Prefecture town. Only after a house in Tibetan style (see Figure 1; House constructed within the Nomadic settlement project on the winter grassland location; Maqin County; October 2009), interpreted as a tiled front and a toilet, was raised, was the owner authorized to get the financial grant of 40.000 RMB. Construction of animal sheds was contracted separately and participant households had to prepay 6.000 RMB to the government in order to obtain double this amount later. By the end of 2009 this money still had not reached the nomads, even when the house construction and the animal shed preparation had been completed months previously.

In Zeku County, Qinghai Province, inhabited mainly by nomads with low incomes in comparison with the nomadic households of Maqin County, the government decided to take charge of all Nomadic settlement project house constructions. The nomads merely had to pay $5.000 \mathrm{RMB}$ per household to get a new house. The general project

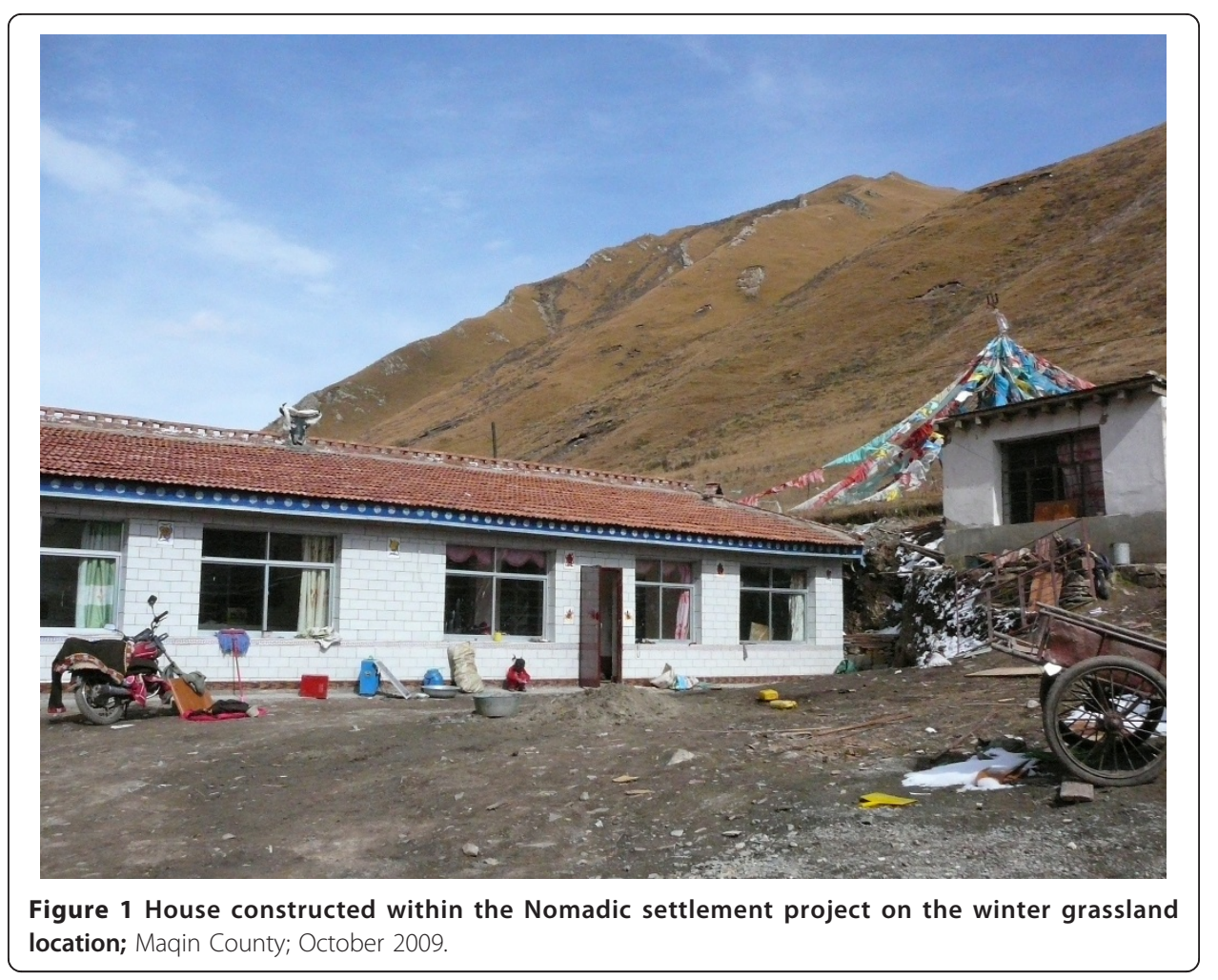


description allows houses to be built on the original winter grassland location, but the local County Government office in charge decided to build all the new houses in uniform settlements near administrative units or at least along the main roads (see Figure 2; Nomadic settlement project constructions; Zeku County; October 2009). Through this plan, the county government saved the highcosts of transporting material to the winter grassland locations.

Poor households with an insufficient number of livestock are the first targeted by the settlement policy. Nevertheless, richer nomads often also want to gain the advantage of a low cost house in the peri-urban area of township or county town, but only if they can retain their original pastureland and livestock. The lack of information obtained by the nomads from government representatives usually leads the nomads having high interest in the project, and a high number of potential project participants. Only later after the contract is signed, most of the contracted nomads find out about the conditions connected to their participation on a resettlement or settlement program. If these conditions mean a partial or total loss of their grassland, the nomads of course dislike it, but cannot do anything about it anymore. Another factor that awakes the interest of nomadic households for settlement houses is the new strict control of children's school attendance in the west of China. There are schools either in the settlements or nearby, which eases the transportation for the children. Therefore there is often higher interest among the nomads than the amount of houses that can be supplied by the government in a given year. During the sedentarisation propaganda in 2009 in Zeku County, the governmental representatives praised the advantages of a cheap house but did not explain the further conditions of the policy. Large numbers of nomads applied. In one affected village in Zeku County, the village leader, facing too high a number of applicants for the settlement, selected program participants by choosing their names

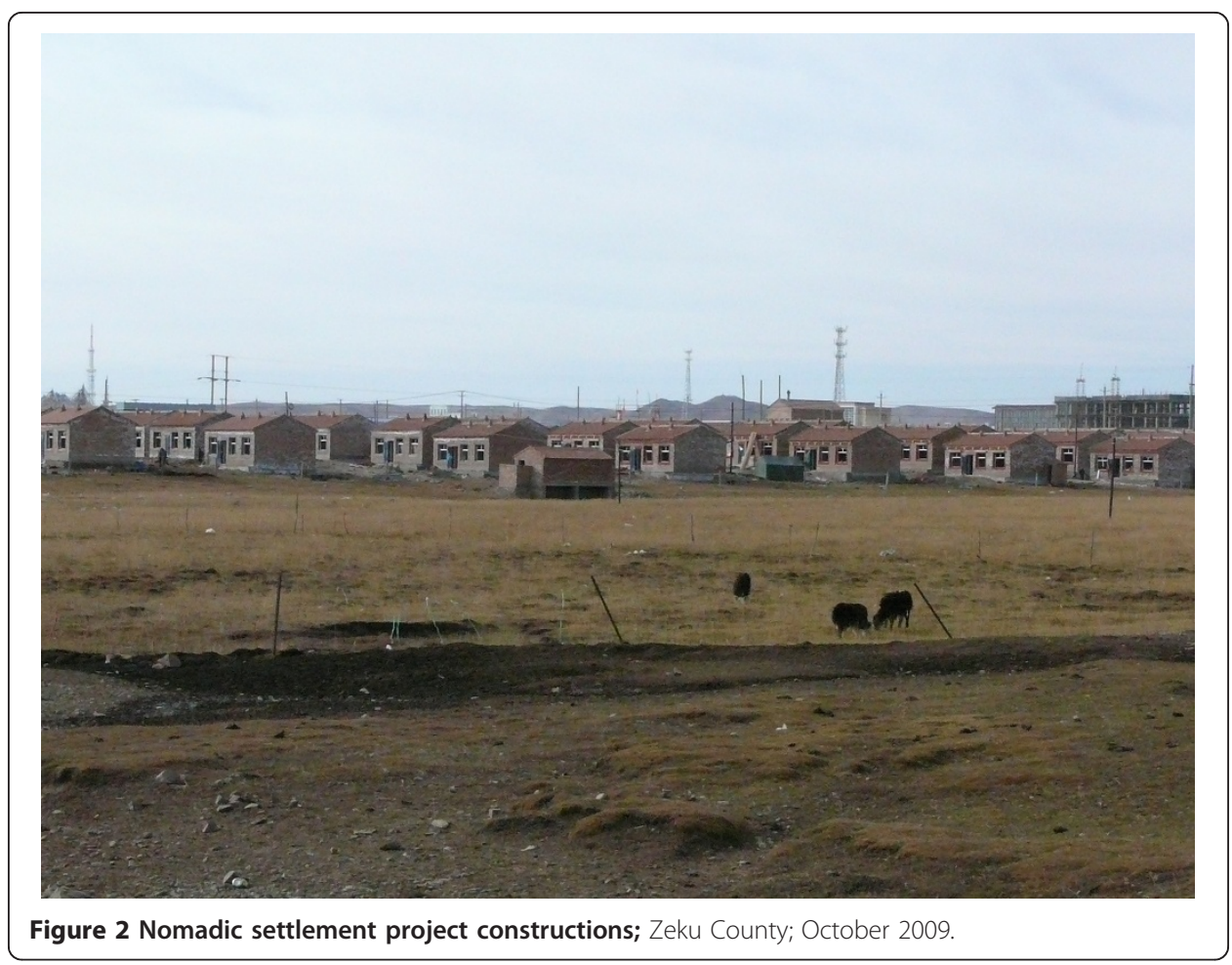


randomly from a hat. Many nomads still can read neither Tibetan nor Chinese and so even when signing the contract, they did not understand the embedded condition that the government had now the right to claim $50 \%$ of the household's grassland. So far, in this case the government has not enforced its right on the grassland and the affected nomads hope that the situation will remain as it is.

In the nomadic area of Hongyuan County in the neighbour Province of Sichuan, the government was also implementing the Nomadic settlement project. The grassland conditions here are relatively good, so the justification for settlement constructions here primarily serves regional development and better political control. Also here these houses create new villages along main roads. New houses in a village are a living base for each nomadic household. They do not have to move their equipment through out the year and the house offers the nomads a chance to accumulate material belongings. The government also hopes that through moving nomadic households closer to urban areas, the nomads will increasingly engage in business and services. According to my research data, only a small number of households actually try to get additional income as drivers or plan to open a restaurant or guest accommodation. Most people in the settlements just use the free time to rest and rely on the food supplements provided by their livestock in the grassland and financial subsidies from the government.

In 2009 each family that applied and was chosen to participate in the Nomadic settlement program in Hongyuan County obtained 20.000 RMB to build a new house. The total amount spent on the constructions was usually much higher, sometimes even over 100.000 RMB. The nomads use their savings to equip the new house with high quality and modern goods (see Figure 3; Inner equipment of a new house, Hongyuan County, October 2009) and additionally enjoy the possibility of a state loan of a further 25.000 RMB that must be repaid during the three following years. Poor households, labelled as such by the township and county government, get a complete house for free together with a small governmental subsidy (see Figure 4; A house constructed for poor households in Hongyuan County; October 2009).

\section{Conclusions}

Until recently the nomads involved in the Nomadic settlement project did not have to meet any obligations concerning pastureland or livestock number reduction ${ }^{\mathrm{d}}$. The financial support for their new houses is an additional governmental assistance. Therefore most of the nomadic households want to use this chance to get the money and build a house, even if this was not absolutely necessary. Officially, participation of nomads on governmental programs such as this is voluntary, nevertheless in some places such as Zeku or Hongyuan County the executive officials made clear to the nomads that a refusal to participate would lead to denial of any future governmental help. Therefore, the nomads usually accepted even those less advantageous conditions included in a resettlement or settlement contract, in order to avoid possible trouble with the local government.

However, at least in the case of houses constructed in separate settlements away from the winter pasture areas, some problems have already occurred. In these locations there is no space to keep livestock and so some households, especially small or rich 


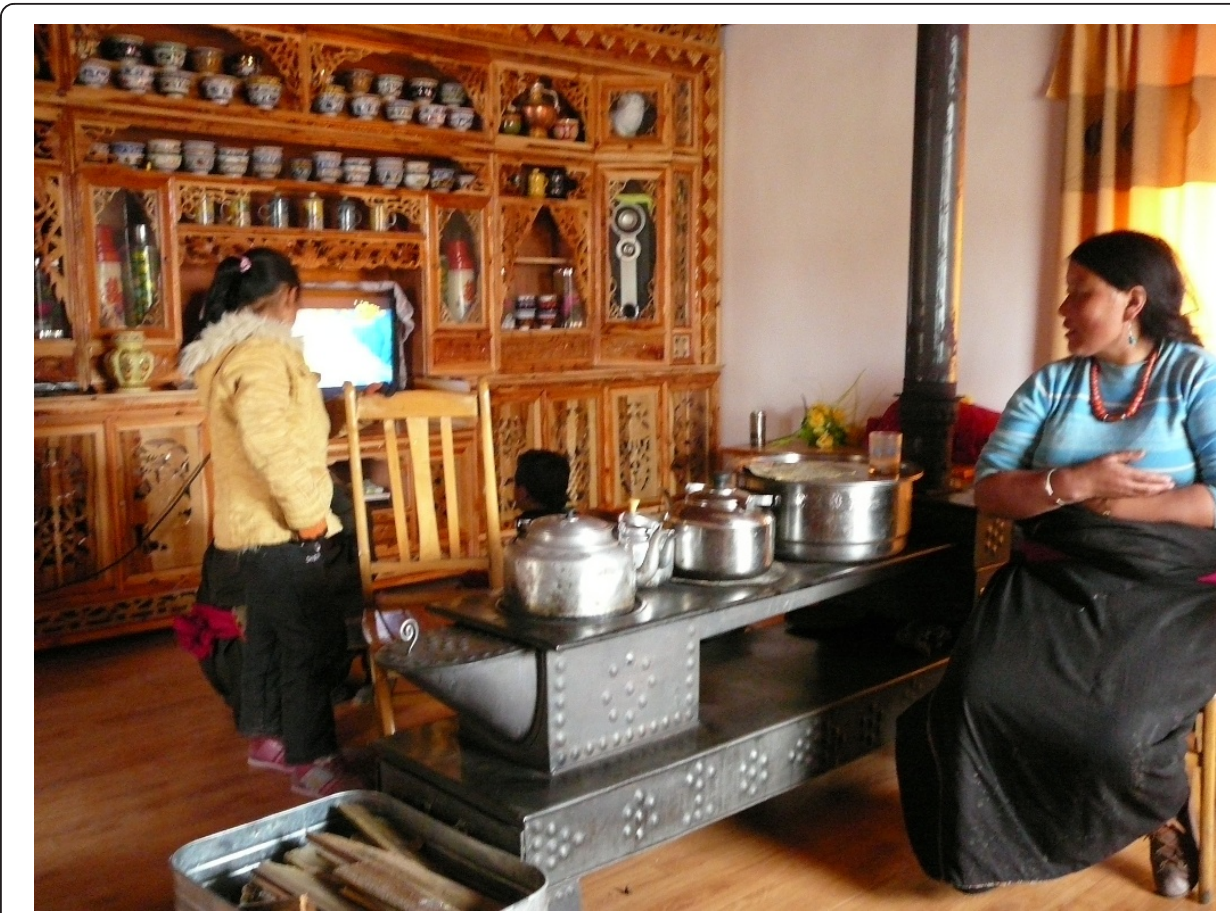

Figure 3 Inner equipment of a new house, Hongyuan County, October 2009.

households, refused to move in, even after the house construction was completed. In such a situation, it depends on the local executive government how it will proceed. Some households who are dissatisfied with the settlement conditions simply sell the house secretly, hoping there will not be any consequences. During my field research

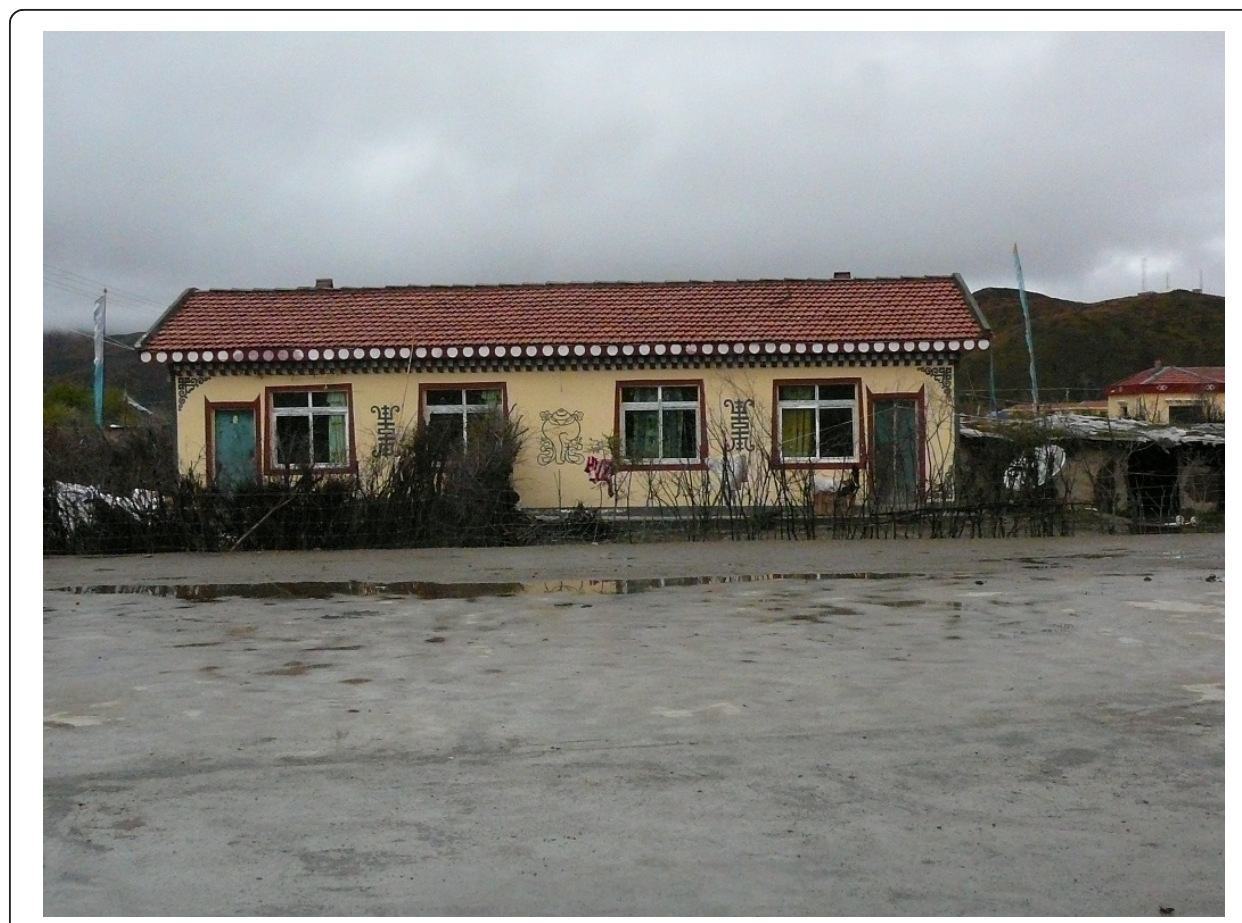

Figure 4 A house constructed for poor households in Hongyuan County; October 2009. 
period the Nomadic settlement project was only in the first phase. The first year settlements were being finished and the nomads were about to move in. Therefore, it was not possible to describe how the government representatives react when the nomads ignore the settlement rules. In most cases however the older generation together with children obliged to attend school reside in the new house, while the middle-aged couple remained on the grassland taking care of the livestock as before. The new houses are comfortable and the road access makes transportation easy, but there are not many new income possibilities for the nomadic households. Besides their knowledge of animal husbandry, their education is usually insufficient. The government hopes that these families could get involved in small businesses and other services mainly for tourism. However, without proper qualifications, this appears to be a difficult issue for the nomads.

So far, the nomadic households involved in the Nomadic settlement project remain dependant on animal husbandry as their main source of income. For the future, this assumes that the nomads will remain using the pastureland and livestock.

Nevertheless the aim of this project, besides providing comfortable living for nomadic households, is a modernisation of animal husbandry. According to the government, a new form should replace the traditional and backward way of Tibetan pastoralism. Through the implementation of the Nomadic settlement project, a new era of modern animal husbandry will begin (ADGM I 2009). This is part of the governmentimplementation plan but it contains no further description of how the development of nomadism shall proceed. Even if the modernisation plan for Tibetan animal husbandry is not available yet, everything implies that in the future the current form of Tibetan nomadism will no longer be existent. All signs suggest that, in order to assimilate the inhabitants of the high plateau better into the rest of mainland China society and to gain closer control over China's western regions, the government is planning to transform the nomadic way of life into a more settled one.

However, the process of sedentarising Tibetan nomads in the Amdo area has already been slowly proceeding for a long time. Now, at least in Qinghai Province it seems that recently with the help of the Nomadic settlement project the process is reaching its final aim.

As was the case in other societies, a change is inevitable also in Tibetan nomad society. 'It is continual and expected, due to the very nature of their way of life. However, change is by no means always synonymous with modernization. Even technological improvements in pastoralist systems aimed at their intensification may have but a limited effect and sometimes even negative collateral consequences' (Ginat and Khazanov 1998). The influence of rushed and forced changes in lifestyle, as in some sedentarisation programs of the central Government in China, might lead to the loss of important cultural aspects of the nomadic society connected to their life on the grassland. Due to a strong dependence on governmental subsidies in the settlements, having lost their own source of income, the nomads might become a despised group on the margin of society. This is happening already among the rural Tibetan community in Tongren town. The attitude towards the nomads changed significantly, after these were moved from their original location on the grassland of Zeku County into a new settlement next to Tongren town. Suddenly, after entering the living space of the rural town-dwelling Tibetans, the nomads were seen as dirty and criminal. 
The fast pace of lifestyle change among the nomadic society might also have an impact on the environment. The lack of mobility caused by enclosing the living space of people and livestock adds also to the severe grassland degradation ${ }^{\mathrm{e}}$ that currently occurs. Older nomads especially worry about long-term grassland enclosures that prevent livestock from grazing in selected parts of grassland. They claim that after leaving the grassland fallow for several years, the complete ecosystem will change and such places will not be suitable for herding at all in the future.

As mentioned before, social change resulting from external conditions and development possibilities is a natural phenomenon and is inevitable. The important issue is that this process must appear spontaneously, consistent with the needs of the particular group. In the case of sedentarisation efforts in nomadic areas of Amdo, the nomads should be more involved in the process of planning and implementation and obtain more detailed information about the details of the implemented policy that concerns them and their pastureland. This might avoid serious trouble for the central Government in the future.

The field research was done during the first year that the Nomadic settlement project was implemented. Therefore, this article can only offer an overview of the current situation and implementation proceedings. Further research over the upcoming years will be necessary, to evaluate all the actual consequences that the Nomadic settlement project, together with earlier sedentarisation efforts of the Chinese government, will bring for the lifestyle and culture of Tibetan nomads, the environment and political control on the Tibetan high plateau.

\section{Endnotes}

a See also: Yeh, E.; Green governmentality and pastoralism in western China: 'Converting pastures to grasslands'; in: Nomadic peoples; Vol. 9 (2005); Issue 1.

${ }^{\mathrm{b}}$ See more in: Du, F; Grain for green and poverty alleviation. The policy and practice of ecological migration in China; in: Horizons; Vol. 9; Nr. 2; p. 46, Yeh, E.; Green governmentality and pastoralism in western China: 'Converting pastures to grasslands'; in: Nomadic peoples; Vol. 9; Issue 1 or Foggin, M.; Depopulating the Tibetan grassland; in: Mountain Research and Development; February 2008.

${ }^{c}$ According to Guoluo Prefecture government announcement from the 14th of September 2009.

d This applies to areas of Hongyuan County in Sichuan, Maqin and Zeku Counties in Qinghai Province, where field research was done.

e See also: Humprey, C.; Sneath, D.; The end of nomadism; Duke University press; Durham; 1999.

\footnotetext{
Competing interests

The authors declare that they have no competing interests.

Received: 13 February 2011 Accepted: 9 May 2011 Published: 9 May 2011

References

Du, F. 2006. Grain for green and poverty alleviation. The policy and practice of ecological migration in China. Horizons 9(2). Foggin, M. 2008. Depopulating the Tibetan grassland. Mountain Research and Development.

Ginat, J, and A Khazanov. 1998. Changing nomads in a changing worldSussex academic press; Brighton.

Goldstein, M. 2010. Beijing's 'People first' development initiative for the Tibet Autonomous region's rural sector - a case study from the Shigatse area. The China Journal.

Gruschke, A. 2005. Nomade, bleib bei deinen Zelten. Das neue China.
} 
Gruschke, A. 2006. Tibet. Nomaden ohne Weide? Eurasisches Magazin.

Jiakuai zangqu you mumin dingju gongcheng jianshe (Speeding up the construction of Nomadic settlement project in Tibetan areas); in Qinghai Daily; 24.04.2009 Primary Chinese sources - Administrative documents concerning grassland management (ADGM).

2003 Qinghai sheng caodi gongzuo ziliao xuanbian 1994 (Selected documents of Qinghai Province grassland work), Qinghaisheng xumuting, Xining, 1995 Primary Chinese sources - Administrative documents concerning grassland management (ADGM).

Qinghai sheng caoye jishu guicheng huibian (Compilation of Qinghai Province grassland technology rules), Qinghai sheng caoyuan zongzhan, Xining, Primary Chinese sources - Administrative documents concerning grassland management (ADGM).

Qinghai sheng tui mu huan cao gongcheng xiangmu guanli banfa (Management measures of Turning pastureland into grassland project in Qinghai Province), in Qinghai sheng tui mu huan cao gongcheng wenjian huibian; Qinghai sheng nongmu ting; Xining; December 2008 Primary Chinese sources - Administrative documents concerning grassland management (ADGM).

Qinghai sheng zangqu you mumin dingju gongcheng 2009 nian shishi fangan (Implementation plan for the Nomadic settlement project in Tibetan areas of Qinghai Provinc in 2009); Qinghai sheng nongmu ting; Xining; April 2009 Primary Chinese sources - Administrative documents concerning grassland management (ADGM).

Sanjiangyuan ziran baohu qu shengtai baohu yi jianshe (Ecological preservation and constructions in the Nature preservation zone of the Three river sources); Qinghai renmin chubanshe; Xining; 2007 Primary Chinese sources Administrative documents concerning grassland management (ADGM).

Sheng zhengfu bangongting zhuanfa sheng nongmuting guanyu 2009 nian zangqu you mumin dingju gongcheng shishi yijian de tongzhi (Notice of suggestions concerning the implementation of the Nomadic settlement project in Tibetan areas in 2009 transmitted by the General office of Province government to the provincial Office of agriculture and animal husbandry); Xining; 2009 Primary Chinese sources - Administrative documents concerning grassland management (ADGM).

Yeh, E. 2003. Tibetan range wars: Spatial politics and authority on the grasslands of Amdo. Development and Change 34

Yeh, E. 2005. Green governmentality and pastoralism in western China: 'Converting pastures to grasslands'. Nomadic peoples $9(1)$.

doi:10.1186/2041-7136-1-4

Cite this article as: Ptackova: Sedentarisation of Tibetan nomads in China: Implementation of the Nomadic settlement project in the Tibetan Amdo area; Qinghai and Sichuan Provinces. Pastoralism: Research, Policy and Practice 2011 1:4

\section{Submit your manuscript to a SpringerOpen ${ }^{\circ}$ journal and benefit from:}

Convenient online submission

- Rigorous peer review

- Immediate publication on acceptance

- Open access: articles freely available online

- High visibility within the field

- Retaining the copyright to your article

Submit your next manuscript at $\boldsymbol{s p r i n g e r o p e n . c o m ~}$ 